\title{
Pan-Canadian review of cancer drugs will not be binding on provinces
}

Previously published at www.cmaj.ca

I $\mathrm{n}$ a bid to encourage a more consistent standard of therapy across Canada, a national oncology drug review process will be launched this fall to provide all provinces except Quebec with common recommendations on the clinical and cost-effectiveness of new cancer drugs.

But patient advocacy groups worry that the new pan-Canadian Oncology Drug Review (pCODR) will fail to smooth the seams in the nation's patchwork access to cancer drugs, as individual jurisdictions won't be held accountable to the review's recommendations when making the final call on which drugs to cover.

Currently, each province conducts its own review of new cancer drugs, which means a duplication of work at the review level, and results in disparities in the formulary listing of individual drugs and their financial coverage across the country, says Colleen Savage, vice president and CEO of the Cancer Advocacy Coalition of Canada.

Although still under development, the new national review process will remedy some of these duplications and discrepancies by offering provinces a single body of evidence to help decide final benefit-listing and coverage, says Kevin Wilson, executive director for the Drug Plan and Extended Benefits Branch at Saskatchewan Health and cochair of the review's interim steering committee.

As part of the review, an expert committee will assess the clinical, pharmacoeconomic, and guideline evidence for oncology drug submissions and provide recommendations. The expert committee will be composed of five to seven oncologists, two pharmacologists, two health economists, two pharmacists, two patient representatives, a physician who is not an oncologist and an ethics expert.

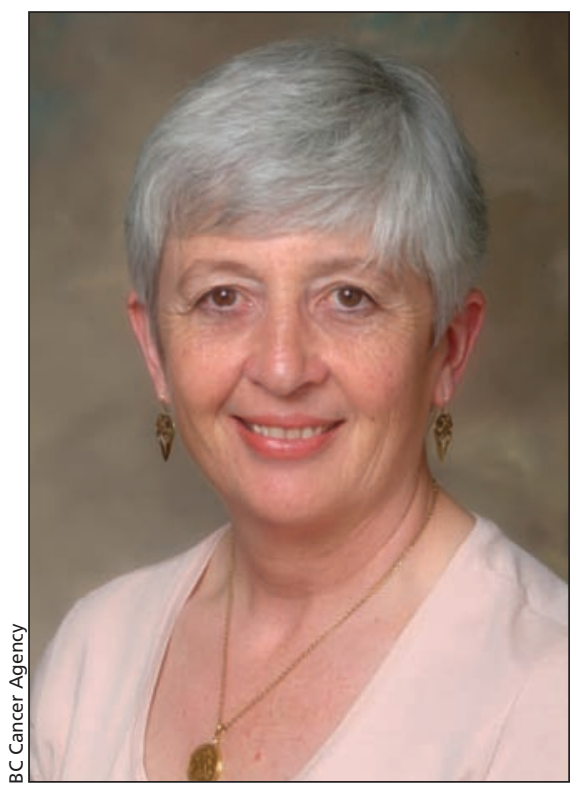

Determining whether a drug is too expensive for provincial formularies is not a scientific decision, but rather, a judgment call, says Dr. Susan O'Reilly, vice president of cancer care at the $B C$ Cancer Agency.

"However, the accountability for funding a treatment, or not funding it and leaving a patient to come up with $\$ 50000$ on their own, rests entirely on the individual provinces," Savage points out. "The provinces may well set their own standard of care, and that's problematic enough, but when they don't follow a recommendation at very least they should be required to explain their reasoning and report back to pCODR."

It would be difficult for a province to reject a positive recommendation unless it had severe financial problems, Dr. Susan O'Reilly, vice president of cancer care at the BC Cancer Agency, believes. "It will be far more contentious when a proposal is rejected, because then there'll be a lot of horsetrading between the provinces and the drug companies to negotiate a workable price."
Accountability and the transparency of the national review are among potential "land mines" to successful implementation of the regime, Savage says. "After all the clinical and expert reviews, after all the costbenefit analysis, pCODR will have to do exactly what the provinces already do, and that's decide whether a drug is too expensive to use. That discussion is not a scientific one, that's a judgment call."

"To date there's been no transparency in how the provinces make this judgment call," she adds.

Among obstacles surrounding the creation of the national review process has been drug company opposition to the inclusion of patient representatives on the expert committee. "One of their biggest concerns regarding public participation on the expert committee was that they' $d$ have access to information that drug companies regard as commercial secrets, where any leakage might have an impact on their competitiveness," O'Reilly explains.

Savage wonders whether the patient representatives will be able to offset the inherent "bias of affordability" that experts and bureaucrats might bring to the table.

"How are these well-meaning, wellbriefed, well-trained individuals going to offset the experts in the room who may say it's unnecessary or too expensive or speak in a jargon that's hard to fathom? What is the price tag for [a drug to be] too expensive, and what is the amount of time in extended life that makes a drug worth the money? If there is a price tag, if there is a cut off, we need to know."

Others have expressed concerns about the initiative's transparency, but O'Reilly says transparency will be achieved through a web portal, to be provided by the Canadian Partnership Against Cancer, which will post results of drug reviews, including rec- 
ommendations and the rationale for the decisions.

"The details still have to be worked out," she says. "Of course these won't be cookie cutter decisions, but there will be a public face explaining what has been recommended."

It is expected that reviews of oncology drugs will be completed within four to five months, which O'Reilly says is an acceptable time frame.

The new review process is still in development, and currently the interim steering committee is working on staff recruitment and a Memorandum of Understanding between its partners, including the Canadian Agency for
Drugs and Technology in Health and the Canadian Partnership Against Cancer.

The final steering committee will be composed of six senior-level representatives from the provinces and four senior-level cancer agency representatives, with representatives from the Canadian Agency for Drugs and Technology in Health and the Canadian Partnership Against Cancer acting as observers.

Development of the national review was set in motion in 2006 by Canada's provincial and territorial premiers. In 2007, an interim Joint Oncology Drug Review initiative was launched, in which Ontario's oncol- ogy drug review process was studied as a model for the national review process, with other provinces participating as observers.

In Canada, $45 \%$ of men and $39 \%$ of women develop cancer in their lifetime, and about one in four die of the disease. A presentation made by the review's cochairs in April indicates that expenditures on cancer drugs and biologics now occupy $30 \%$ of provincial cancer budgets and the annual growth rate of oncology drug sales is roughly double that of the overall pharmaceutical market. - Lauren Vogel, Ottawa, Ont.

DOI:10.1503/cmaj.109-3262

\section{National standards for electronic health records remain remote}

Previously published at www.cmaj.ca

$\mathrm{T}$ en years after the federal government agreed to build a national "infostructure" for electronic health records (EHRs), confusion and disarray appear to be the only form of national standards in operation within health information record-keeping circles.

Several physicians and academic experts say the political will to implement national standards appears non-existent. EHR vendors are fuming. Health Canada stepped into the fray by introducing new certification and licensing requirements, some of which are fuzzy. Canada Health Infoway, meanwhile, has thrown its hands into the air and says it has no authority to compel provinces to comply with national standards.

And federal Auditor General Sheila Fraser again waded into the murky EHR waters on Apr.20 and updated a November 2009 report that concluded Infoway has had little success in removing interprovincial barriers and, therefore, little "assurance that EHR systems will be correctly implemented."

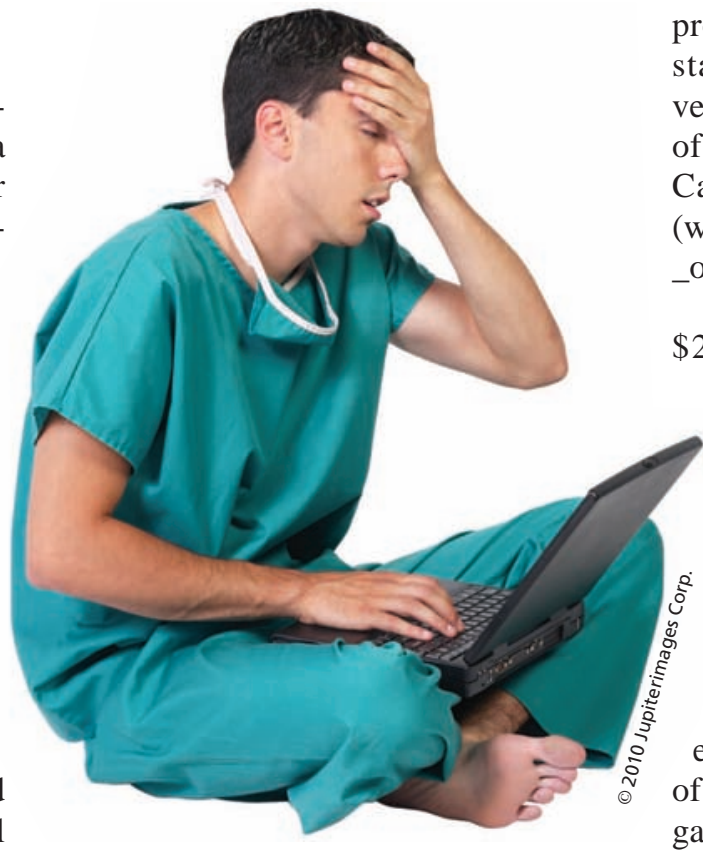

provinces continue to create separate standards that oblige national EHR vendors to conform to a dizzying array of local requirements instead of panCanadian standards, Fraser reported (www.oag-bvg.gc.ca/internet/docs/parl _oag_200911_04_e.pdf).

The incongruities compromise the $\$ 2.1$-billion federal investment in

Infoway and present "risks to high-quality health care, patient safety, and the privacy of patient information," Fraser added.

Some observers say the problems start at the top.

"We don't really have any federal governance," says Dr. Alexander Jadad, Canada Research Chair in ehealth innovation at the University of Toronto in Ontario, Princess Margaret Hospital physician and founding director of the Centre for Global eHealth Innovation.

Jadad, who recently chaired a panIssues relevant to clinicians have not been addressed in the development of standards for electronic health records, some experts say.

Instead of a single national marketplace for electronic health information products such as software for managing patient medical records, many
European meeting at which 27 other governments agreed to adopt unified standards, says successful integration of interjurisdictional EHR systems depends on high-level political leadership. Coherent national standards are "a clear priority and governments 